\title{
Experimental study on hydraulic rock damage
}

\author{
Junzhe Li Jun Zhang ${ }^{\mathrm{a}}$ Lixia Sun ${ }^{\mathrm{a}}$ \\ a.The university of science and technology of Liaoning \\ zj.777@163.com(114051)
}

\begin{abstract}
Keywords: rock; hydraulic damage experiment; lateral crack strength;curve and equation; damage degree
\end{abstract}

\begin{abstract}
The mechanical properties of rock mass change significantly in water pressure, and causing coal-rock mass deformation and instability, then leading to significant engineering accident. Based on hydraulic damage experiment to explore the mechanical process that water pressure prompted crack propagation, so as to induce the damage evolution of rock mass, mechanical process to produce strength damage. The hydraulic damage experiment was carried out in the condition of various confining pressure and pore pressure, the corresponding confining pressure and pore pressure curves of rock were fitted out; And the damage degree of rock mass was defined basing on the lateral hydraulic strength, getting the lateral crack strength damage degree under different confining pressure, that reveals the uniformity between the hydraulic changing and the rock samples damage; the key points were interpolated in curve of the damage degree and the confining pressure, the fitting equation of the damage degree and the confining pressure was got; The hydraulic rock damage experiment has important theoretical and practical significance to study on the long-term stability of rock engineering.

The water existence in the rock has strongly affected the rock's deformation and stability. The water has not only produced the hydrostatic pressure and seepage force but also has some affection on its mechanical property, which usually lowers the rock's intensity index. According to the statistics, the damage of nearly $90 \%$ natural side slope and manmade slope has some connections with the underground water and 30\% 40\% dam accidents have some connections with the rock vadose $^{[1,2]}$ The vadose field's existence and change is one of the importance reasons that cause the imbalance of the rock project and that can even cause the large-scale geology disaster The crevice vadose pressure fasten the rock's crack initiation、 extension、 penetration, macroscopically, this is also a process caused by the vadose, because the vadose can cause the rock strength's weak or damage, on the other hand ${ }^{[3-8]}$, the change of the rock's stress and the extension of the rock' damage can also lead to the change in its vadose features and it will change the distribution of the vadose field. ${ }^{[9-11]}$ We should give a application of three-axis simulating experimental system for hydraulic fracturing study and carried out a large size hydraulic fracturing of rock crack propagation studies. ${ }^{[12]}$ Therefore the experimental study on hydraulic fracturing in rock damage on rock engineering, slope project, tunnel project and other areas has broad application prospects.
\end{abstract}

\section{The experimental study on hydraulic fracturing in rock damage}

\section{The experimental purposes}

Because most rocks belong to the sedimentary rocks, which have the characteristics of joint fissure in the process of its accumulation and transformation of the earth' crust. After the digging of the strip mine, the rock experienced damage and deformation, secondary interstice, a lower intensive under the influence of the excavation. However, under the influence of the water pressure 
in the rock's side slope system, because the water's affection, the rock will be damaged by the water pressure, which is called after damage. Except the physical chemistry damage of the water, the damage also caused by the water's pressure. The experience of the damage of rock body in water pressure is an important way to know the crack expansion mechanism, through simulation slope body in the rock body of assigned conditions and the rock's tensile strength joint fissure damage regulation in the lateral water pressure, and to be monitored of the actual physical process of the crack expansion, meanwhile we are searching for the factors that affect the rock's crack and do the separation reach on it. These all have significance meanings for the right realization of the theory of the water press lead to the crack expansion and establish a more realistic numerical model.

\section{The experimental principle and the damage degree}

\section{The experimental principle}

An important indicator of hydraulic rock damage, expressed as:

$$
D=1-\left(\sigma_{p w} / \sigma_{p d}\right.
$$

In this formula: D-- the damage degree of the strength of the rock mass lateral water pressure; $\sigma_{\mathrm{pw}^{-}}$Saturated specimen transverse crack intensity; $\sigma_{\mathrm{pd}^{--}}$Dry sample strength of transverse crack.

Mostly cranny or larger weak structure exist in rock mass. When the weak structure is connected with the ground, it will become water and enter the inner channels of rock mass. If there is high water pressure on the upper part of rock mass, pore pressure $\sigma_{\mathrm{p}}$ will be produced in the weak side. The so-called "pore pressure" produced by water pressure in rock mass structural plane is the main factor of rock burst, which have two kinds of influence on rock burst. The first one is when normal pressure component $\sigma_{\mathrm{n}}$ of tectonic pressure in weak rock mass surface is much smaller than the pore water pressure $\sigma_{\mathrm{p}}$, and $\sigma_{\mathrm{p}}$ is large enough, it can directly make the rock mass damage fracture and deform. The second one is when $\sigma_{\mathrm{n}}>\sigma_{p}$, there are two kinds of induced rock slope instability mode. One is partly fracturing in the similar direction with the principal stress $\sigma$, and its shallow part deform extensionally. $\sigma_{\mathrm{p}}$ can make this part rupture and tensile rupture occur. The other is $\sigma_{\mathrm{p}}$ reduces $\sigma_{\mathrm{n}}$ on the fracture, which reduces rock shear strength in the same depth and causes the rupture whose tectonic pressure is already close to rock mass strength to slip rupture.

Hydraulic rock damage experiment is taken to investigate the mechanical process of the water pressure prompting crack extension, so as to induce the damage evolution of rock mass and create intense damage. The experiment system consists of test machine, water pump, load device, control system and other auxiliary equipment. Its principle of structure is showed in picture 1.1: 


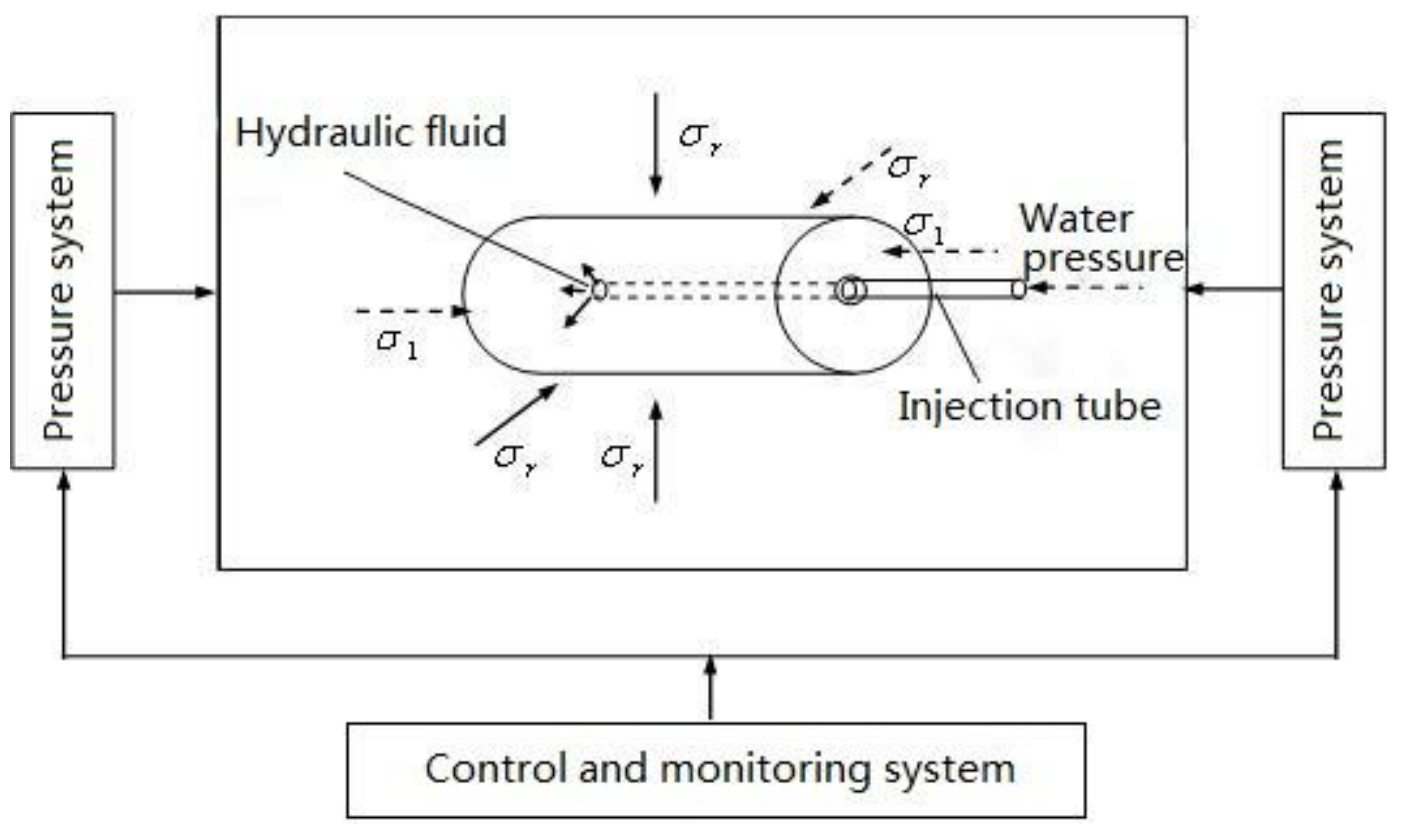

Fig.1.1 Test schematic diagram

\section{Damage degree}

The pore water pressure of the pressure caused by the damage of rock mass is one of the effective method for quantitative evaluation of rock mass damage. Prefabricated hole in the lateral pressure and containing Shuicheng correlation, lateral pressure also reflects the high water pressure of rock mass, and lateral water pressure strength and the damage degree of rock mass.

\section{Experiment preparation}

\section{Sandstone sample}

Sample is collected from drill cores, the depth in 10 100 M. Sample have bedding. The core drill, immediately sealed with wax paper, and maintain the original rock environment in the natural state.

Specimen processing, open the sealed sample, fix in the special fixture, drill set the core specimen by vapor dual-purpose drilling, then stone sawing machine sawing grinding as required, smoothen the surface by sandpaper, then detect and correct it in horizontal platform, and ultimately make uniform diameter of $39.1 \mathrm{~mm}$, height $50 \mathrm{~mm}$ cylindrical specimens, number, record natural and preserve sealedly.

Samples 1,2 are sandstone samples, from the same layer of rock, No.2 is in the same direction as the prefabricated hole; specimen No.3 and No.4 are mudstone specimen, from the same rock mass, No.4 is in the same direction as the prefabricated hole, this experiment considers the strength of the three state, that is, the dry state, natural state and saturated state. A total of 12 experiments were conducted in 4 groups.

\section{Dry specimen}

The dry part of the specimen is to make the test pieces of water loss, the experimental use the natural air-drying method, Indoor ventilated place, natural air drying at room temperature.

\section{Water saturation}

Method and procedure: (1)the piece is placed in the saturated container, pumping into a vacuum state, and then continue for half hour;(2) Gradually add water to the specimen height of $1 / 2,2$ / 3, respectively, pumping gas into a vacuum, we continue to pump half an hour; (3)add water to specimen height of $95 \%$, pumping gas into a vacuum, continue to pump half an hour; (4)When water beyond the test above a height of $2 \mathrm{~cm}$, soak for 10 days in calm water; (5)in 2.0MPa under hydrostatic pressure continuous soak for 10 days; (6) continue to soak under the room temperature 
and atmospheric pressure, take out before the experiment.

\section{Experimental procedure}

Load: (1)Applying the pre tightening shaft pressure to make the test piece stable and prevent the pressure from the central hole of the confining pressure. (2)Slowly confining pressure to a predetermined value. (3)Change the surface and gradually enlarged pore pressure to the rupture of the specimen.

Records: (1)the pressure sensor transform pore pressure changes into the voltage variable, input dynamic strain gauge; (2)the outer wall of the sample, along the axial and circumferential directions symmetrically affixed with a pair of resistance strain gauge. The two direction of the strain with the pore pressure synchronous input dynamic strain gauge; (3)the pore pressure and strain signal amplified by strain gauge and then input $\mathrm{X}$-Y function recorder.

\section{Experiment results}

\section{Experimental results of water pressure induced rock damage}

Fig1.2 (a - - (d) is Coal rock confining pressure and pore-water pressure rupture strength curve, abscissa $\sigma_{\mathrm{r}}(\mathrm{MPa})$ represents confining pressure, ordinate $\sigma_{\mathrm{pc}}(\mathrm{MPa})$ represents the pore-water pressure rupture strength, The graph is called $\sigma_{\mathrm{r}}-\sigma_{\mathrm{pc}}$ curve.

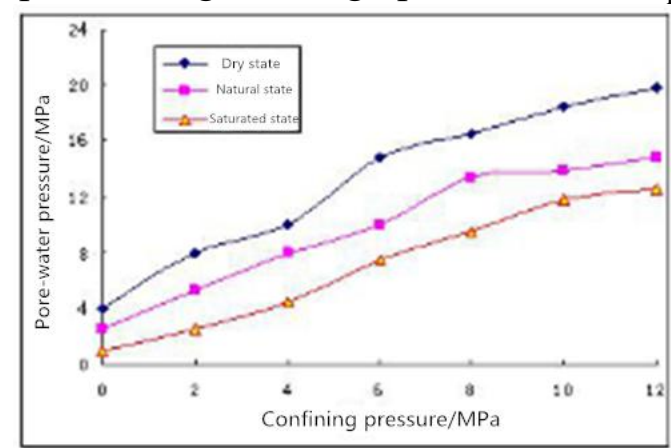

Fig 1.2 (a) First group

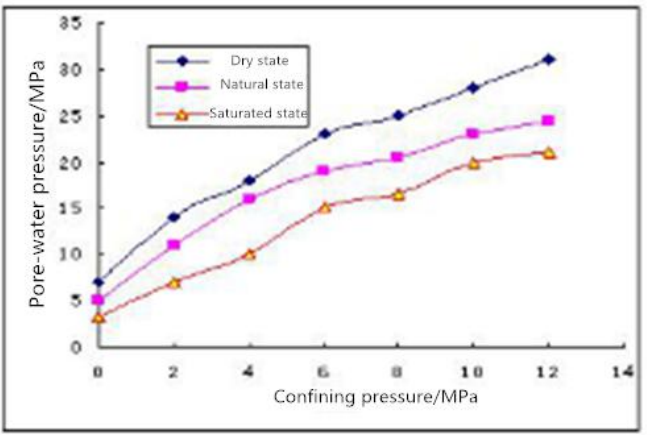

Fig 1.2 (c) Third groups

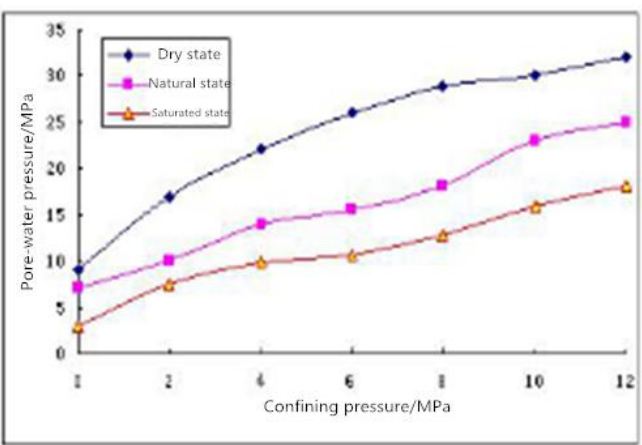

Fig 1.2 (b) Second groups

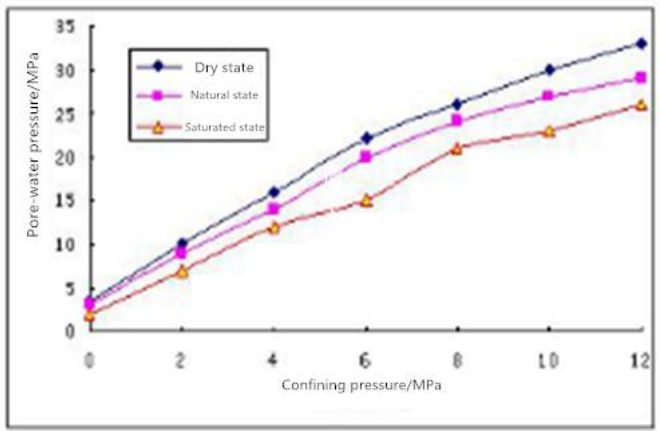

Fig 1.2 (d) Fourth groups

Fig1.2 Rock confining pressure - pore-water pressure rupture strength curve

Table 1-1 is crosswise broken strength damage degree under different confined pressure, Table $1-3$ is the fitting curve of sandstone damage degree and confining pressure, Table 1-4 is the fitting curve of mudstone damage degree and confining pressure. 
Tab.1-1 crosswise broken strength damage degree under different confined pressure

\begin{tabular}{lcccccccc}
\hline & & She & \multicolumn{6}{c}{ Transverse crack strength damage degree of different confining } \\
$\mathrm{N}$ & Rock & $\begin{array}{c}\text { ar } \\
\text { o. }\end{array}$ & samples & join \\
\cline { 5 - 8 } & $\mathrm{t}$ & $2 \mathrm{MPa}$ & $4 \mathrm{MPa}$ & $6 \mathrm{MPa}$ & $8 \mathrm{MPa}$ & $10 \mathrm{MPa}$ & $12 \mathrm{MPa}$ \\
\hline 1 & $\begin{array}{c}\text { sandsto } \\
\text { ne }\end{array}$ & Yes & 0.601 & 0.542 & 0.492 & 0.426 & 0.360 & 0.368 \\
& $\begin{array}{c}\text { sandsto } \\
\text { ne }\end{array}$ & No & 0.572 & 0.542 & 0.590 & 0.560 & 0.466 & 0.436 \\
3 & $\begin{array}{c}\text { mudsto } \\
\text { ne }\end{array}$ & Yes & 0.493 & 0.401 & 0.346 & 0.339 & 0.288 & 0.325 \\
4 & $\begin{array}{c}\text { mudsto } \\
\text { ne }\end{array}$ & No & 0.303 & 0.249 & 0.319 & 0.191 & 0.232 & 0.210 \\
\hline
\end{tabular}

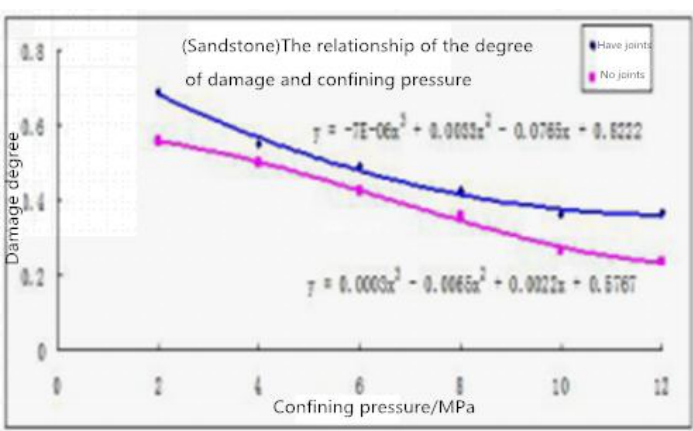

Fig.1.3 the fitting curve of sandstone damage degree and confining pressure

\section{Interpretation of result}

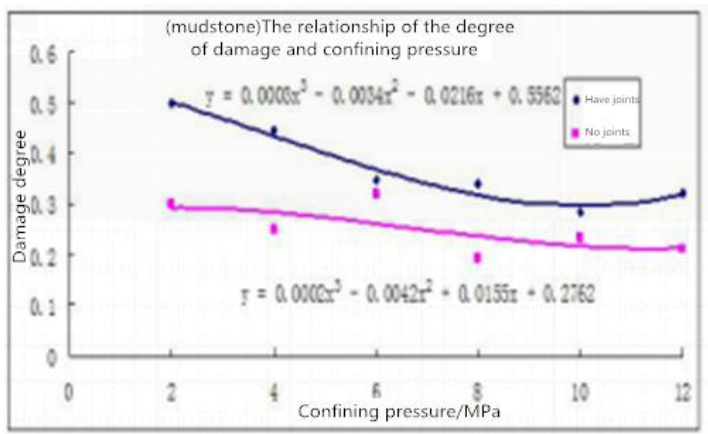

Fig.1.4 the fitting curve of mudstone damage degree and confining pressure

(1) Using the lateral water pressure to characterize the pore water pressure in the rock, the damage of the coal rock mass is tensile damage, and the rupture is tensile rupture.

(2) The strength of the dry sample was greater than that of the natural state and the saturated water sample, and the strength of the rock during the process of filling was damaged, and the damage to the pore water pressure was also the characteristic of the water saturation.

(3) The structural surface has great influence on the strength of rock joints, so the presence of joints makes the crack strength $\sigma_{\mathrm{pc}}$ damaged.

(4) Crack strength $\sigma_{\mathrm{pc}}$ increases with the increase of confining pressure,when the confining pressure is low,$\sigma_{\mathrm{pc}}$ increases linearly with the increasing of $\sigma_{\mathrm{r}}$; when $\sigma_{\mathrm{r}}$ increases to a certain value, $\sigma_{\mathrm{pc}}$ with the growth rate of $\sigma_{\mathrm{r}}$ decreases gradually, the relationship between the two becomes nonlinear.According to the change tendency of the curve, when the growth rate of high confining pressure becomes zero, $\sigma_{\mathrm{pc}}$ is a constant.

The relationship formula of $\sigma_{\mathrm{r}}-\sigma_{\mathrm{pc}}$ curve linear:

$$
\sigma_{p c}=\sigma_{p}+k \sigma
$$

In the formula, when $\sigma_{\mathrm{r}}$ equals zero, $\sigma_{\mathrm{p} 0}$ is the crack strength, $k=\Delta \sigma_{p c} / \Delta \sigma_{r}, \Delta \sigma_{p c}$ and $\Delta \sigma_{r}$ are respectively the incremental of $\sigma_{\mathrm{pc}}$ and $\sigma_{\mathrm{r} \text {. }}$

(5) The test results showed that the fracturing strength of coal and rock damage increase with the confining pressure increasing,any affected by joints and fissures,containing intersection of 
jointed rock fracturing strength damage degree than does not contain the intersection of jointed rock fracturing strength damage degree.

Damage degree and confining pressure meet three polynomial relations:

$$
D=a \sigma_{r}^{3}+b \sigma_{r}^{2}+c \sigma_{r}+d
$$

In the formula, $\mathrm{D}$ means crack strength damage degree of rock mass, $\sigma_{\mathrm{r}}$ means confining pressure, and $\mathrm{a}, \mathrm{b}$ and $\mathrm{c}$ can be calculated by the experimental data.

\section{Conclusion}

The experimental study on the damage of rock mass caused by water pressure is the evolution law of water pressure in the process of coal rock damage. The test of rock mass damage caused by coal rock specimen is carried out, and the following results are obtained:

typical rock samples of the experimental data analysis, fitting different confining pressure when transverse fracturing strength damage degree, damage degree and confining pressure relationship curve fitting, the curve shows, rock fracturing strength damage degree increases with the confining pressure increasing increases, damage degree by joint effect of containing intersection of jointed rock fracturing strength damage degree than does not contain the intersection of jointed rock fracturing strength damage degree.

damage degree and confining pressure fitting equation

According to the fitting curve of the relationship between the damage degree and the confining pressure, the key points of the given number and the test points are interpolated, and the fitting equation of the damage degree and the confining pressure is fitted.

Through the water pressure induced rock damage experiment, the strength curve of rock confining pressure and pore water pressure is obtained, and the fitting curve and equation of confining pressure and water damage intensity equation and the relationship between the rock damage degree and confining pressure are obtained.

\section{References}

[1] 1997, 22(5): 482-485. Zhang Jincai Liu Tianquan Zhang Yuzhuo.Study on the permeability of fractured rock mass[J].Journal of china coal society, 1997, 22(5): 482-485.

[2]1998,17(6):662-666. He Manchao; Yao Ai-jun.Study of mechanical functions of underground water in slope rockmass[J].Journal of rock mechanics and engineering,1998,17(6):662-666.

[3]2004. Wang Laigui.The pivotal scientific issues of the exploitation of coal resources in harmony with the environment[R]. National Natural Science Foundation project application report,2004.

[4] 2008.01-2010.12.Wang Jianguo etc.Open-air tall slope deformation and evolution in the coupling of complex factors[R].National Natural Science Foundation concluding report,2008.01-2010.12.

[5] 2006,25(7):97-98.Wen Dejuan,Teng Shouren, Yang Zirong,Bai Yinhua, The study on the water filling factor of the third open pit mine[J].Coal Technology,2006,25(7):97-98.

[6] 1999.05:26-28.Nicolachin.Integreted approach of filling water to closure open-air stope[J],Metal mines abroad,1999.05:26-28.

[7]2005,10(5):4-5.Dong Yige,Liu Xiue,Xu Yanchun.Use Seepage finite element method to simulate the influence to the face from the loose aquifer[J].Coal mining,2005,10(5):4-5.

[8] 2008,20(1):29-30.Zhang Ziping,Li Yonglu. Hydrogeological conditions and water filling factors analysis of Feng Ji Ditch Coaliery[J].Coal geology of China,2008,20(1):29-30. 
[9]2012.6. Wang Zhenwei. the study on seepage-damage coupling laws of water filled coal （rock） slope[D], Liaoning Technical University doctoral dissertation, 2012:27-31.

[10]2010.6. HE Feng. The study on mechanism of rock creep-seepage coupling[D], Liaoning Technical University doctoral dissertation, 2010:2-10.

[11]2011.36(1):39-42.HE Feng,Wang Laigui etc.Criteria for coal creep rupture and its application[J].journal of china coal society, 2011.36(1): 39-42.

[12] 2010,35(10):1765-1766.HUANG Bing-xiang, Research on Theroy and Application of Hydraulic Fracture Weakening for Coal-Rock Mass[J].Journal of china coal society, 2010,35(10):1765-1766. 